\title{
Social Work Education: A Vehicle for Innovative Practice
}

\author{
Cynthia L. Garthwait
}

\begin{abstract}
In light of continuous social change and the uniqueness of social problems faced by the clients of professional social workers, practice innovations are constantly needed to better address problems, strategies are needed to deal with emerging and challenging problems, and a commitment to innovate in the midst of ongoing treatment interventions due to changing client situations is necessary. Social work educators, in a unique position of preparing students for professional practice that focuses on knowledge, skills and values, can effectively teach innovation as a necessary facet of practice. Seeing innovation through its intellectual, affective, ethical, and societal and client drivers, social work educators can pose questions to students that can be creatively answered, at least in part, through both academic and field experiences.
\end{abstract}

Index Terms-Emerging practice, social work education, social work innovation.

\section{INTRODUCTION}

Professional social workers are ethically committed to competent, appropriate, and evidence-based practice with their clients at all levels of intervention, including work with individuals, families, groups, organizations, communities, and societies. Their practice is to be based on empirically based knowledge and social work ethics [1].

Such practice demands that social work education equip students at the bachelors and masters degree levels with sound theoretical foundations, current knowledge, and helping skills matched to client need. Holding the profession to a high standard of ongoing development and innovation is challenging in light of the difficult social problems addressed by social workers such as poverty, violence, racism, mental illness, and addiction. Addressing such problems, which are dynamic in nature and complex in their etiology, requires professionals who can intervene armed with theoretical foundations, a sound evidence base for practice, and innovation when working with clients at all levels, including individuals, families, organizations, communities, social change, and policy formation. Research-based knowledge gained primarily from traditional research may not be an adequate source of understanding client situations, so including clients as research partners is needed but may also be "a paradigm shift away from authority based practice traditional in social work "[2].

Social work educators have the responsibility to prepare students for empirically sound practice and the additional obligation to teach students the importance of innovation when needed. "Social work education shapes the profession's future through the education of competent

Manuscript received May 5, 2014; revised July 8, 2014.

Cynthia L. Garthwait is with the University of Montana, Missoula, Montana, CO 59812 USA (e-mail: cynthia.garthwait@umontana.edu). professionals, the generation of knowledge, and the exercise of leadership within the professional community" [3]. This paper will discuss the higher education context of teaching students to be innovators, offering ways of thinking about professional social work education that effectively responds to changing societal, community and personal conditions and trends. Combining professional education and ways of thinking about innovation occurring in "the depths of incubation" is challenging but necessary [4]. Innovation as a broad-based, holistic endeavor will be described, as will the relationship between innovation and best practices in social work practice.

\section{SOCIAL Work CONCEPTIONS OF INNOVATION}

A number of discreet but inter-related factors drive innovation, which means they necessitate, encourage, promote, and at times require social work innovation. These drivers come from within the profession itself, from client groups served, and from societal contexts.

\section{A. Drivers of Innovation}

\section{1) Intellectual drivers of innovation}

For the professional social worker, the cognitive dimension of innovation involves high order thinking about not only what clients need in terms of social work interventions, but about theoretical and empirical bases for work with varied clients. Professionals who can innovate must be trained to understand, utilize, analyze, research, and critique existing practice theories and models, and need to understand the importance of evaluating interventions with a mixed methodology that includes attention to effectiveness, efficiency, fidelity to a particular model, and ethical parameters of practice. "Innovation is the need to address a particular problem in the practice arena, whether it is micro, mezzo or macro, and the search for evidence ore research that addresses the problem. The translation or transportation of the research involves critical analysis of the evidence and a critical appraisal of its application to a particular client population, a contextual setting, client preferences, ethical concerns, resource and training needs, and the skills and knowledge of the practitioner once the intervention is implemented, then it must be evaluated, on a programmatic or individual level or as a policy" [5].

The intellectual dimensions of innovation to be taught in school of social work involve not only understanding existing practice models, but scanning the social environment for emerging needs and promising approaches which purport to address those needs. Social work educators can also guide students in viewing themselves as practice researchers and/or research practitioners who can measure the effectiveness of their own work. In addition, such practitioners must develop skills in conceiving of, 
designing, and implementing innovative approaches that either better address existing needs or develop approaches to address newly identified needs.

\section{2) Affective drivers of innovation}

The affective, emotional dimension of innovation which social work education can foster includes an ability to develop empathy for clients given their challenging circumstances. Such a connection between social workers and clients carries a level of emotional investment in a shared commitment to enhanced social functioning for the client and family. Such a commitment can be described as "workplace spirituality" because it is the motivation to make a difference through work that has meaning and purpose [6]. This commitment to the welfare of others as both a commitment to others and a need for professional meaning is often manifested in a strong, continual restlessness with the status quo, which may be seen as less and less effective and innovative over time. Educators can build upon and maximize this restless commitment by channeling student energy into academic learning about what will enhance quality of life for clients. Educators can also prepare students for the frustration often experienced by social workers in the field over very real limits to using innovative practices. These limits may be financial, structural, attitudinal, and competency-based, and educators can train students to identify these frustrating limitations in their practice and develop ways to prevent them from blocking needed innovation.

\section{3) Ethical drivers of innovation}

Social workers and the educators who prepare them for practice are ethically bound to continuously assess their own effectiveness, and to develop innovative approaches which can demonstrate measurable outcomes. Innovative practice may also require innovative evaluation and research methods to measure effectiveness. Such ethical principles as service to others, human rights of clients, practice competency, and contributions to the knowledge base of the profession provide the foundation for academic learning that is values-based and guided by a commitment to overall social justice. Thus, social work innovation is philosophically driven, and should be encouraged because it will lead to understandings that go beyond practical applications only [7]. Newly minted social work professionals must also be trained to identify and prevent any erosion in the ethical dimension of innovation, which is fueled by professional fatigue, disappointing results, and the intractable nature of social problems, cynicism, and lack of resources to do better.

Although innovation in theoretical terms is hard to argue with, innovation brings with it some risk, experimentation, and working on the margins of effectiveness and accountability. When applied to the lives of real clients with real problems, innovative practice has an element of risk for harm by nature of its untested effectiveness. Both social workers and the educators who prepare them for practice must consider this carefully and ethically.

\section{4) Societal drivers of innovation}

By their very nature, changing societal conditions require improved social work practice through emerging and promising approaches. At times the reform of both treatment and social policies is needed when they are no longer relevant or effective because they do not take into account new issues or evolving social issues. Because the social work profession views society as a vehicle for promoting positive social functioning of its citizens, practice must be guided by information provided by societal representatives and social indicators. Social work educators can teach students to recognize the interplay between the welfare of individuals and the welfare of social groups and societies, and to use them as both informants and resources. Students being encouraged to find novel solutions to societal problems must learn the importance of stakeholder involvement in the search for understanding [8].

It is incumbent on social work educators to identify and encourage the intellectual characteristics and skills needed for innovative social work practice, including intellectual curiosity, understanding of various sources of knowledge, appreciation for creativity, and an attitude of learning. Applying these characteristics to an understanding of societal needs is vital for practicing social workers. Social work educators must identify classroom and field experiences for their students which foster such attitudes and approaches to their work, including a professional ability to "notice" the need for improvement, change, innovation, and a mission of developing and utilizing best practices.

\section{5) Client drivers of innovation}

Both positive and negative experiences with clients can illuminate the need for practice innovations. Clients, when empowered as partners in their interactions with social workers, can speak to the need for modified, improved, or totally new approaches to their unique problems and built upon their unique strengths. Clients can drive such a quest for innovation, and can be consulted as the experts on their own lives. In addition, when "social workers actively look for, promote, and support the natural strengths within people and systems to empower them to grow and thrive," clients often develop their own knowledge, theory and approach to change [9].

Social work education must reinforce the conception that the needs of clients, not funding limitations or organizational priorities, should be the primary focus of intervention. Students who inform their practice through meaningful communication with their clients will be likely to identify and use innovations that professionals would not have identified on their own. In addition, clients may also be organizations seeking change, communities in need of development, neighborhoods being organized for change, social policies in need of reform, and social change efforts aimed at achieving social justice.

\section{B. Barriers to Innovation}

Competency in innovative social work practice includes recognition of the to-be-expected, sometimes troubling, and challenging barriers to conceptualizing innovations, integrating them into existing services, and evaluating their effectiveness. Anticipating such barriers and forces against program improvement and creative approaches to social problems will help new social workers prepare for the experience of having to advocate for innovation, convince others of the promise of innovation in meeting 
organizational missions, and create a culture of learning which supports emerging and promising approaches.

\section{1) Attitudinal barriers}

Attitudinal barriers which can discourage and confound new social workers are those which are in direct conflict with the idealistic, enthusiastic, and hopeful nature of beginning professionals committed to social change. German philosopher Arthur Schopenhauer (1788-1860) is said to have described the stages of new truth. "First, it is ridiculed. Second, it is violently opposed. Third, it is accepted as being self-evident." Social work educators can prepare students to anticipate barriers such as this and others including apathy, lack of knowledge, need for training, negative belief systems, cynicism, lack of vision, and defensiveness.

Practicing social workers and social agencies generally do not have the time for knowledge generation for its own sake because of the time demands of their work. However, this may limit the development of new ideas generated by "tinkering" which could then gain momentum when applied to practice settings [10]. Such attitudinal barriers on the part of professional colleagues, supervisors, and administrators, often based on good faith attempts at change and program renewal, can surprise and discourage new practitioners unless they are taught to anticipate and deal with such limiting factors and forces against change.

\section{2) Institutional barriers}

Organizations, social policies, and social systems also possess and express institutional barriers which serve to maintain the status quo rather than facilitate innovation in practice. Such barriers include financial constraints, uncertain funding, staff turnover, the acceptance of the status quo, insufficient professional energy for innovation, lack of continuing education, timing, lack of accountability, a culture that effectively discourages change, and a bureaucracy with policies that standardize services but which also serve to stifle creativity. In addition, "Although social innovation happens all around us, many promising ideas are stillborn, blocked by vested interests or otherwise marginalized. The competitive pressures that drive innovation in commercial markets are blunted or absent in the social field and the absence of institutions and funds devoted to social innovation means that too often it is a matter of luck whether ideas come to fruition, or displace less effective alternatives. As a result, many social problems remain more acute than they need to be [11]. Effective social work education includes a focus on recognizing such barriers and working to challenge them with knowledge, capacity building, professional development, and a commitment to the welfare of those served.

\section{Pedagogical Methods for Teaching InNovation}

\section{A. Understanding Practice Standards}

For both social work students and social work educators, innovations in practice are best understood and utilized when seen in the context of overall evaluative levels of practice. Students and new practitioners need to see the difference between practices which are acceptable and those which are exemplary, and social work educators can use the following table to illustrate the levels of excellence in the field, as evaluated by the profession itself through experience and research evidence.

As Table I demonstrates, the social work profession develops new ideas and incorporates them into practice models that range in level of excellence from standard of practice to best practice. Social work educators can help students understand the difference between these, and then develop their skills through internships in organizations which use approaches that could range from standard of practice to best practice. When teaching innovation in practice, social work educators can use specific practice examples to help students see how innovation fits into the evaluative levels of practice, and that innovation can be done at any of the levels illustrated above.

TABLE I: EVALUATION CONCEPTS WHICH GUIDE PRACTICE [12]

\begin{tabular}{|c|c|c|}
\hline $\begin{array}{c}\text { Evaluation } \\
\text { Concept }\end{array}$ & Definition & Uses \\
\hline $\begin{array}{l}\text { Standard } \\
\text { of Care }\end{array}$ & $\begin{array}{l}\text { Generally agreed upon } \\
\text { minimum standard for } \\
\text { provision and quality of } \\
\text { services }\end{array}$ & $\begin{array}{l}\text { Provides basic level of } \\
\text { expectation for services } \\
\text { as understood by } \\
\text { practitioners, agencies, } \\
\text { and professional } \\
\text { organizations }\end{array}$ \\
\hline $\begin{array}{l}\text { Accepted } \\
\text { Practice }\end{array}$ & $\begin{array}{l}\text { Generally agreed upon } \\
\text { approach to the provision } \\
\text { of services to clients with } \\
\text { specific needs and } \\
\text { resources }\end{array}$ & $\begin{array}{l}\text { Provides common, } \\
\text { standardized approach } \\
\text { for services to clients } \\
\text { with similar needs and } \\
\text { resources }\end{array}$ \\
\hline $\begin{array}{l}\text { Emerging } \\
\text { Practice }\end{array}$ & $\begin{array}{l}\text { Innovative and promising } \\
\text { approaches based on } \\
\text { advances in orienting / } \\
\text { explanatory theories and } \\
\text { the practice models } \\
\text { associated with them, but } \\
\text { which are not yet fully } \\
\text { evaluated empirically }\end{array}$ & $\begin{array}{l}\text { Promotes the } \\
\text { development of } \\
\text { improved services and } \\
\text { outcomes for specific } \\
\text { populations, allows for } \\
\text { adaptations of accepted } \\
\text { practice, and } \\
\text { incorporates emerging } \\
\text { knowledge into existing } \\
\text { practice }\end{array}$ \\
\hline $\begin{array}{l}\text { Evidence- } \\
\text { based } \\
\text { Practice }\end{array}$ & $\begin{array}{l}\text { Empirically tested and } \\
\text { affirmed approaches } \\
\text { which are based on } \\
\text { accepted orienting / } \\
\text { explanatory theories and } \\
\text { which have demonstrated } \\
\text { effectiveness over time }\end{array}$ & $\begin{array}{l}\text { Provides standardized } \\
\text { and effective services } \\
\text { based on empirical } \\
\text { testing and allows for } \\
\text { ongoing testing of } \\
\text { innovative approaches }\end{array}$ \\
\hline $\begin{array}{c}\text { Best } \\
\text { Practice }\end{array}$ & $\begin{array}{l}\text { Recommended practice } \\
\text { approaches found to be } \\
\text { most effective and of } \\
\text { highest quality, combined } \\
\text { with guidelines for } \\
\text { incorporation into practice } \\
\text { at the individual, agency, } \\
\text { social policy, or research } \\
\text { level }\end{array}$ & $\begin{array}{l}\text { Promotes highest } \\
\text { standards for service } \\
\text { provision, provides } \\
\text { criteria upon which to } \\
\text { build intervention, and } \\
\text { ensures quality of } \\
\text { practice at all levels }\end{array}$ \\
\hline
\end{tabular}

\section{B. Teaching Innovation as Standard Practice}

Because social work students can be expected to be enthusiastic, motivated, idealistic, and willing to try new approaches while learning to master accepted models of practice, social work education can focus on identifying, reinforcing, and equipping students with knowledge, skills and values related to practice innovations. Beyond these basics, which are both foundational and profound when applied to actual practice, creative learning activities can assist students in understanding, applying, analyzing, critiquing and developing effective practices. The following areas of social work education highlight the need for 
innovation when social problems intensify over time, when current approaches and models fail or become stagnant, and when new opportunities become available.

\section{Pedagogical Approaches to Innovation}

Social work educators must not only prepare students for competency in existing services and programs, but also prepare students to evaluate their own practices, improve them, and innovate through the creation of new ideas and services. Following are several pedagogical approaches to innovation that could guide course development, skill achievement, competency building, and forward thinking in students.

Social work educators can design their learning experiences around the definitions of innovation in social work. Students need to understand and build upon the following:

- The variety of definitions of innovation which exist and impact practice

- Client definitions of innovation as customized interventions that meet their individual needs

- Ethical mandates for innovation

- Viewing innovation as improving existing practice

- Viewing innovation as new practice

Social work educators can help students recognize the necessary for innovation in practice. Students need competency and beginning mastery of the following:

- Ability to identify unaddressed client needs that require innovation

- Ability to measure quality of services provided as a prelude to innovation

- Skills in identifying promising and emerging practices to meet client needs

- Commitment to collaborate with stakeholders to stimulate innovation

- The ethical obligation to continuously improve services.

Social work educators must help students conceptualize innovation as a process requiring both promoting change and resisting negative influences on innovation. Students need skills in making innovation a reality by understanding the need for the following:

- Creating a culture of innovation in their organizations.

- Fostering creativity, flexibility, tolerance for ambiguity and risk-taking

- Spanning professional boundaries to prevent silos of professional knowledge

- Resisting pressures to remain stagnant, maintain the status quo and discourage change

Social work educators must develop and utilize learning experiences that help students achieve an understanding of and skills in implementing and evaluating innovations in practice. Students need competency in the following:

- Piloting innovative approaches

- Involving stakeholders in implementation

- Tolerating disruption while maintaining a vision
- Implementing change as incremental, partial, wholesale, and hybrid

- Developing innovative research methods to evaluate innovative practice

These social work innovation skills can be promoted while students learn the basics of current approaches, building upon student idealism, passion and commitment to addressing challenging social problems and promoting positive social functioning. Educators must be creative and flexible themselves when teaching such skills, trusting the teaching and learning process to result in creative thinking. "Creativity is difficult to program. It is individual, a product of passion and intellect, the natural inclination of iconoclasts who thrive on taking risks and challenging the status quo" [13].

Social work pedagogy in the area of innovative practice can include a wide variety of teaching tools, learning experiences, and critical thinking assignments. Modeling practice innovation by utilizing innovations in teaching, educators must design academic learning that requires students to learn not only existing practices that might have been innovative at one time, but that also requires students to view their profession as one which must continually innovate to be effective.

Classroom learning can include:

- Studying the history of existing social services in a particular field of social work practice, which helps students recognize that services and methodologies evolve over time.

- Studying the impact of the social environment on the success or failure of innovation, including the drivers of innovation and the barriers to innovation described above.

- Writing and committing to a personal mission statement for social work practice.

- Studying historical social workers who assumed leadership in innovation at the micro, mezzo and macro levels of practice.

- Participating in service-learning courses in which didactic content and real community-based experiences are combined to facilitate learning and skill development.

Internships and practicum experiences can include:

- Interviewing social workers about their experiences with innovation in practice.

- Researching best practices and emerging practices and comparing them with the services in their internship organization.

- Asking professionals outside the social work profession to examine and evaluate agency practices from a non-social work perspective to stimulate interdisciplinary thinking.

- Asking clients to suggest changes and improvements in services that would better meet their needs.

\section{Discussion OF QUESTIONS FOR TEACHING AND LEARNING}

Social work educators, through both classroom didactic 
and experiential learning activities, can prepare students for innovative practice by modeling innovative teaching practices themselves, which includes openness to student ideas, input and innovation. Through the use of internships and practicum placements, educators can also arrange for and supervise integrative and applied real-life experiences which challenge students and help them acquire skills and competencies necessary discussions, debates, skill-building, writing exercises, and real social work activity in the field can also be used to teach and to facilitate learning.

Educators can design learning experiences which will address the following innovative practice questions that students, clients, and social workers ask and attempt to answer.

\section{A. Perspectives on Innovation}

- What is innovation and why is it needed?

- Who gets to decide what is effective? The client? The social worker? Society? Funding sources?

- What is the client role in innovation?

\section{B. Organizational Context of Innovation}

- How and why do organizations grow and change for the better?

- Is there a workable balance between innovation and pragmatism?

- Where does innovation fit in the decision tree model of treatment selection?

- How can risk, chaos, and disruption support or impact innovation?

\section{Societal and Political Context of Innovation}

- What forces in the community are for and against innovation? Why?

- What can history tell us about innovation?

- Are best practices realistic?

- In what ways is innovation a political issue?

\section{Evidence Based Practice}

- Is practice that is not evidence-based considered ethical?

- When is "good enough" acceptable?

- How is evidence defined?

- Does the focus on measuring outcomes of innovation have any negative impacts?

\section{E. Social Justice Context of Innovation}

- Which clients receive services considered to be best practices and which do not? Why?

- In what ways could innovation be considered a human rights issue?

Social work educators must also ask themselves pedagogical questions which range from ethical inquiries about their teaching responsibilities to knowledge questions about the practice wisdom they can share with students. Potential questions that social work faculty members and social work programs could ask themselves when designing courses, practicum experiences, and new program initiatives include the following:
- What is our essential message about innovation in social work practice?

- What is our essential message about best practices in social work practice?

- Are we using innovative and best practices in teaching?

- To what degree are we modeling innovation to students?

- What experiences will teach, challenge, inform, and encourage our students to be innovators?

- What is our responsibility to the clients my students will serve?

- What is our responsibility to the growing knowledge base of the profession of social work?

- How can we teach students about the ethics of competency?

\section{Conclusion}

Social work educators, often practitioners themselves, have a broad, necessary mission to prepare students and graduates for the very challenging profession they have chosen. Students, though motivated and idealistic, will encounter not only encouragement for innovation, but also disincentives and barriers to innovation. Through sound and yet innovative pedagogical approaches which include holistic learning strategies in the affective, cognitive, and ethical arenas of education, social work educators are in a unique position to contribute to the ongoing effectiveness of their students' eventual practice. They can take satisfaction in knowing that their commitment to excellence in teaching can promote excellence in practice, particularly if they demonstrate through their innovations in teaching that innovation matters.

\section{REFERENCES}

[1] NASW Code of Ethics, Silver Spring, MD, USA: NASW Press, 2008.

[2] M. O. Howard, "Teaching evidence-based practice: toward a new paradigm for social work education," Research in Social Work Practice, vol. 13, no. 2, pp. 234-259, March 2003.

[3] Commission on Accreditation, "Educational policies and accreditation standards," Council on Social Work Education, Alexandria, VA, USA, 2008.

[4] S. Berkum. The Myth of Innovation, Sebastopol, CA, USA: O'Reilley Media, Inc. 2010, p. 11.

[5] S. Mathieson and M. Hohman, "Revolution of an evidence-based practice scale for social work," Journal of Social Work Education, vol. 49 , no. 3, p. 452, summer 2013.

[6] A. Saks, "Workplace spirituality and employee engagement," Journal of Management, Spirituality and Religion, vol. 8, no. 4, pp. 317-340, 2011.

[7] R. A. Este, Raising the Alarm-An Explanation of Innovation and Philosophical Denial: Advances in Innovation Education, Boston, MA, USA, 2013, pp. 89-109.

[8] G. Bhardwaj, J. C. Camillus, and D. A. Houhshell, "Continued corporate entrepreneurial search for long-term growth," Management Science, vol. 52, no. 2, pp. 248-261, February 2006.

[9] A. Rogers, Human Behavior in the Social Environment, $3^{\text {rd }}$ ed., New York, USA: Routledge, 2013, p. 17.

[10] M. Bettiol, V. Finotto, E. Di Marea, and S. Michelli, "Knowledge in the Making," Department of Management, Universita Ca Foscari Venezia Working Paper No. 20148, p. 11, April 2014.

[11] S. Mulgan, S. Tucker, R. Alic, and B. Sanders. "Social innovation: What it is, why it matters and how it can be accelerated," Skoll Center for Social Entrepreneurship, Oxford SAID Business School, p. 5, 2007. 
[12] C. Garthwait, The Social Work Practicum: A Guide and Workbook for Students, $6^{\text {th }}$ ed., Boston, MA: Pearson Education, 2014, p. 195.

[13] S. Osborne and L. Brown, Handbook of Innovation in Public Services, Northampton, MA: Edward Elgar Publishing, Inc. 2013, pp. 36-37.

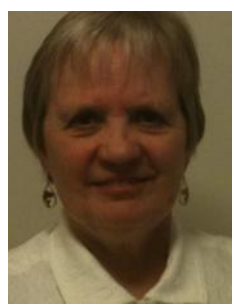

Cynthia L. Garthwait was born in Dodgeville, Wisconsin, USA in 1948, who received her bachelor of arts in psychology and sociology from the University of Wisconsin / Platteville and her master of science in social work from the University of Wisconsin/Madison

She has taught social work at the University of Montana in Missoula, Montana, USA since 1988. There she has served as a professor, the chair of the School of Social Work, the practicum director, and the director of the Baccalaureate Social Work Program. She also served as a faculty field instructor at Eastern Washington University, and has worked as a social worker in the fields of aging, addictions, child welfare, and mental health. She maintains a private practice through which she provides training, consultation and program evaluation. She is the author of the social work practicum: A guide and workbook for students, Boston, MA Pearson education, 2014, which assists students to integrate their academic classroom learning with their field practicum experiences. Her teaching and practice areas of expertise include aging, addictions, human behavior, and spirituality in social work practice.

Professor Garthwait is a member of the American Association of University women, The Montana gerontology society, and the national association of social workers. She has received honors and awards for academic advising, innovative service learning course development, and for emerging leader status. 